There is a limit of 300 words for letters to the editor. Health Affairs reserves the right to edit all letters for clarity, length, and tone. Letters can be submitted bye-mail, letters@healthaffairs.org, or the Health Affairs website, http:// www.healthaffairs.org.

\section{Quality Of Life And Medical Costs: The Authors Reply}

Norman Edelman makes an important point. Medical interventions that improve one's quality of life certainly play an important role in the US health system. But they also play a role in other countries' health systems.

Our paper (Nov 2010) did not explore the extent to which higher costs in the United States might be driven by treatments that primarily improve quality of life rather than survival. There is limited comparative evidence on quality of life, but it is unlikely that elective procedures and treatments aimed at improving quality of life alone are the main drivers of the much higher costs in the United States relative to other countries.

For at least some of the procedures that Edelman noted, such as joint replacements, the rates are not excep- tionally high in the United States, and many other life-enhancing procedures and treatments are not very costly. ${ }^{1}$ A more likely culprit is unwarranted diagnostic procedures, which lead to excessive interventions and can thus generate both high costs and poor health outcomes. ${ }^{2}$

Peter A. Muennig Columbia University NEW YORK, NEW YORK

Sherry A. Glied US Department of Health and Human Services WASHINGTON, D.C.

\section{NOTES}

1 Merx H, Dreinhofer K, Schrader P, Sturmer T, Puhl W, Gunther KP, et al. International variation in hip replacement rates. Ann Rheum Dis. 2003; 62(3):222-6.

2 Studdert DM, Mello MM, Sage WM, DesRoches CM, Peugh J, Zapert K, et al. Defensive medicine among high-risk specialist physicians in a volatile malpractice environment. JAMA. 2005;293(21): 2609-17. 